\title{
COVID-19 Pandemi Sürecinde Demanslı Bireyler: Sağlık Profesyonelleri ve Bakım Verenler İçin Öneriler
}

\author{
Merve Aliye AKYOL ${ }^{1}$ (D) Özlem KÜÇÜKGÜÇLÜ² ${ }^{2}$ Burcu AKPINAR SÖYLEMEZ
}

${ }^{1}$ Araş. Gör. Dr., Dokuz Eylül Üniversitesi, Hemşirelik Fakültesi, İç Hastalıkları Hemşireliği Anabilim Dalı, İzmir. Dokuz Eylül Üniversitesi, Evde Bakım

Uygulama ve Araştırma Merkezi, İzmir, Türkiye.

${ }^{2}$ Prof. Dr., Dokuz Eylül Üniversitesi, Hemşirelik Fakültesi, İç Hastalıkları Hemşireliği Anabilim Dalı, İzmir. Dokuz Eylül Üniversitesi, Evde Bakım Uygulama ve Araștırma Merkezi, İzmir, Türkiye.

${ }^{3}$ Doç. Dr., Dokuz Eylül Üniversitesi, Hemşirelik Fakültesi, İç Hastalıkları Hemşireliği Anabilim Dalı, İzmir, Türkiye.

\section{Öz}

COVID-19 pandemisi tüm dünyada milyonlarca insanı özellikle de demanslı bireylerin bakımını hiç kuşkusuz ki olumsuz şekilde etkilemektedir. Demans, yaşlanan toplumların pandemisi olarak adlandırılmaktadır. Demans ve COVID-19 pandemisinin birlikteliği, sağlık profesyonelleri ve aile üyeleri için demanslı bireylerin bakımını daha da zor ve karmaşık hale getirmektedir. COVID-19 pandemi sürecinde demanslı bireylerin var olan sağlık durumlarını koruma, güvenliklerini sağlama, ihtiyaç duyulan desteğin sağlanması konuları daha fazla önem kazanmıştır. Alzheimer's Disease International ve demans uzmanları, tüm dünyada demanslı bireylere ve bakım verenlerine acilen destek olunması gerektiğini belirtmektedir. Bu derlemeyle COVID-19 pandemi sürecinde demanslı bireyin bakımından sorumlu sağlık profesyonellerinin ve aile üyelerinin bakım süreçlerinde kullanabileceği pratik öneriler sunarak onların yollarına ışık tutmak amaçlanmaktadır.

Anahtar Sözcükler: COVID-19, Pandemi, Demans, Bakım Verenler.

\section{Abstract}

People with Dementıa During COVID-19 Pandemic: Recommendations for Health Professionals and Caregivers

The COVID-19 pandemic undoubtedly affects millions of people around the world, especially the care of people with dementia. Dementia is called the pandemic of aging societies. The coexistence of dementia and the COVID-19 pandemic makes caring for people with dementia even more difficult and complex for healthcare professionals and family members. During the COVID-19 pandemic, the issues of protecting the existing health status of people with dementia, ensuring their safety, and providing the necessary support became more important. Alzheimer's Disease International and dementia experts state that people with dementia and their caregivers should be supported urgently around the world. The aim of this review is to shed light on the pathways of healthcare professionals and family members responsible for caring of a person with dementia during the COVID-19 pandemic process by providing practical suggestions that they can use their care processes.

Key Words: COVID-19, Pandemic, Dementia, Caregivers.

Geliş Tarihi / Received: 06.01.2021 Kabul Tarihi / Accepted: 21.05.2021

Correspondence Author: Merve Aliye AKYOL, Araș. Gör. Dr., Dokuz Eylül Üniversitesi, Hemșirelik Fakültesi, İç Hastalıkları Hemșireliği Anabilim Dalı, İzmir, Türkiye. Tel:+902324124774 e-mail:merve.akyol@deu.edu.tr

Cite This Article: : Akyol MA, Küçükgüçlü Ö, Akpınar Söylemez B. COVID-19 Pandemi Sürecinde Demanslı Bireyler: Sağlık Profesyonelleri ve Bakım Verenler İ çin Öneriler. Dokuz Eylül Üniversitesi Hemşirelik Fakültesi Elektronik Dergisi. 2021;14(3): 277-282 
OVID-19 tüm Dünya'da milyonlarca insanı özellikle de 65 yaş ve üzeri bireyleri olumsuz şekilde etkilemektedir (1). Yaşlılık döneminde immün sistem yanıtının azalmasıyla birlikte enfeksiyon riskinde artış görülmektedir. Bu durum yaşlı bireylerin COVID-19 ile enfekte olma ihtimallerini artırmaktadır (2). COVID-19 vakalarının yaklaşık \%20-40'ını 65 yaş ve üzeri bireyler oluşturmaktadır $(3,4)$. Amerika'da COVID-19'a bağlı ölümlerin \%80'ini 65 yaş ve üzerindeki bireyler oluşturmaktadır (5).

Dünyada neredeyse tüm toplumlar yaşlanmakta ve demans, yaşlanan toplumların pandemisi olarak adlandırılmaktadır (6). Tüm dünyada 50 milyondan fazla demanslı birey olduğu ve her 3 saniyede bir yeni vaka ortaya çıktığı bilinmektedir (7). Demans ve COVID-19 pandemisinin birlikteliği, demanslı bireyler ve bakımdan sorumlu sağlık profesyonelleri ve aile üyeleri için çeşitli sorunlara yol açmaktadır. Alzheimer's Disease International ve demans uzmanları, tüm dünyada demanslı bireylere ve bakım verenlerine ivedilikle destek olunması gerektiğini belirtmektedir (8). COVID-19 pandemi sürecinde demanslı bireylerin mevcut sağlık durumlarını koruma, güvenliklerini sağlama, sağlık profesyonelleri ve aile üyeleri tarafından ihtiyaç duyulan desteğin sağlanması daha da önem kazanmıştır (9).

Bu derlemeyle COVID-19 pandemi sürecinde demanslı bireyin bakımından sorumlu sağlık profesyonellerinin ve aile üyelerinin bakım süreçlerinde kullanabileceği pratik öneriler sunarak onların yollarına 1şık tutmak amaçlanmaktadır.

\section{COVID-19 Pandemi Sürecinde Demanslı Bireyler}

\section{Gelişme}

Sosyal mesafe, izolasyon ve hijyene dikkat etme gibi COVID-19 önlemleri, virüsün yayılmasını engellemek için etkili olmakla birlikte, bu önleme çabalarının duygusal ve psikososyal etkilerinin demanslı bireylere etkisi henüz bilinmemektedir (10). Telekomünikasyon konusunda çok az bilgiye sahip olan ve günlük rutinlerinde birine bağımlı olan demanslı bireyler kendilerini yalnız ve terk edilmiş hissedebilmektedir (8). Demanslı bireyler çeşitli koruyucu önlemleri (el hijyeni, öksürürken ağzını ve burnunu kapatmak, sosyal mesafeye uymak, COVID-19 semptomlarının izlenmesi, kendini izole etme...) anlamakta, hatırlamakta ve bunlara uyum sağlamakta zorlanabilmektedir. Bu nedenle kendilerine ve yakın çevresine virüs bulaşma/bulaştırma riski artmaktadır (9). Erken evredeki demanslı bireylerin pandemi süreciyle daha iyi başa çıkabildikleri ve bu süreçte karşılaşılan potansiyel zorluklar hakkında farkındalıklarının olduğu belirtilmektedir $(9,11)$. Fakat hafif kognitif bozukluğu veya erken evre demansı olan bireylerde apati ve/veya depresyon varsa önlemleri uygulama konusunda isteksiz olabilecekleri ve uyum sağlamakta zorlanabilecekleri vurgulanmaktadır. Orta ve ileri evre demaslı bireyler, kısa süreli bellekte ve genel bilişsel durumda bozulma nedeniyle bu önlemlerin çoğunu anlamakta, hatırlamakta ve benimsemekte zorlanmaktadırlar. Mevcut durumu tam olarak anlayamayan ileri evre demanslı bireylerin bile COVID-19'un neden olduğu stres ve duygu durum değişimlerini çevrelerindeki bireyler ve medya aracılığıyla fark edebildikleri düşünülmektedir. İleri evre demanslı bireyler evde kalma, sosyal mesafeye uyma (evde ya da bakım hizmeti sağlayan kurumlarda) ve bakım hizmeti sağlayıcılar tarafindan giyilen ve onların tanınmasını zorlaştıran koruyucu kıyafet kullanımını anlamakta güçlük yaşayabilmekte $(9,12)$ ve bu durum onların kapana kısılmış, terk edilmiş ve korkmuş hissetmelerine neden olabilmektedir. Cagnin ve arkadaşları (2020) tarafından yapılan 4.193 demanslı bireye bakım verenin katıldığı araştırmada, demanslı bireylerin \%59.6'sının var olan nöropsikiyatrik semptomlarının kötüleştiği (en sık irritabilite apati, ajitasyon ve anksiyete), \%26'ında yeni semptomların ortaya çıktığ 1 (en sık irritabilite ve uyku bozukluğu) ve \%26.7'sinin ilaçlarında düzenlemeye ihtiyaç duyduğu bulunmuştur (13). Demanslı bireylerin nöropsikiyatrik davranış sorunları izolasyonu sürdürmeyi güçleştirmekte (14) bu nedenle demanslı bireyler enfeksiyonu kapma ve yayma konusunda daha yüksek risk altına girmektedirler $(8,15)$.

Aktivitelerde, bilişsel fonksiyonlarda azalmanın demanslı bireylerde deliryuma neden olduğu ve bu durumun morbiditeye katkıda bulunabileceği belirtilmektedir. Stres nedeniyle artış gösteren nöropsikiyatrik semptomların bilişsel fonksiyonlarda gerilemeye katkıda bulunabileceğine dair kanıtlar bulunmaktadır (16). Demanslı bireylerin bilişsel ve işlevsel fonksiyonlarında kötüleşme kurum bakımı alma sürecini hızlandırabilmektedir. Salgın sürecinin yönetiminde gündüz bakım merkezleri ve evde bakım hizmetlerinin azalması, arkadaş ve akraba ziyaretlerinin sınırlanması ya da olmaması nedeniyle demanslı bireylerin ihtiyaçlarının tespit edilememe veya yeterince karşılanamama riski bulunmaktadır (9).

\section{COVID-19 Pandemi Sürecinde Demanslı Bireylere Bakım Verenler}

Salgın sürecinde demanslı bireylere bakım ve destek sağlayan sağlık profesyonelleri, aile üyeleri ve yakın çevresindekiler bazı zorluluklarla karşılaşmaktadır.

Bakım verenler, bakım verdikleri bireyleri hastalıktan korumakta zorlandıklarını, hastalarının hijyen, maske ve mesafe gibi temel kurallara uyum sağlamakta zorlandıklarını bu nedenle hem kendilerinin hem de bakım verdikleri bireyin enfekte olmasından endişe duyduklarını ifade etmişlerdir. Bakım verenler pandemi sürecinde kendi sağlık sorunlarında sağlık hizmeti kullanımını kısıtladıklarını çünkü bu süreçte virüsle enfekte olmaktan korktuklarını belirtmişlerdir. İhmal etmek zorunda kaldıkları sağlık sorunlarının giderek kötüleştiğini ifade etmişlerdir. Ayrıca, bakım verenler, demanslı bireylerin yeniden şekillenen yaşam tarzı nedeniyle birçok sosyal aktiviteden uzak kaldıklarını bu nedenle de hastalık sürecinin olumsuz etkilendiğini, yeni gelişen ya da kötüleşen davranışsal sorunlarla da baş etmekte zorlandıklarını ve buna bağlı psikolojik zorluklar yaşadıklarını belirtmişlerdir (17). Bakım verenlerde ortaya çıkan psikolojik semptomlar demanslı bireylerin nöropsikiyatrik semptomlarını daha da kötüleşebilmekte ve kısır bir döngü oluşmaktadır. Karantina sürecinde, bakım verenlerin \%65.9'unun stres kaynaklı semptomlara sahip olduğu belirlenmiştir. Bu bireylerde anksiyete (\%45.9), çaresizlik (\%34.2), distress (\%29.3), irritabilite (\%26.4), terk etme (\%22.0) ve depresyon (\%18.6) görüldüğü saptanmıştır. Bakım verenler tarafından deneyimlenen stresin demanslı bireylerin var olan nöropsikiyatrik semptomlarını kötüleştirdiği (Odds ratio:2.6) ve yeni semptomların ortaya çıkmasına neden olduğu (Odds ratio:1.6) bulunmuştur (13).

Kısıtlamalar nedeniyle, poliklinik hizmetlerinin çoğu iptal edilmekte ya da ertelenmektir. Virüsle enfekte olma riskini azaltmak için bazı bakım verenler, verdikleri bakıma destek olması amacıyla işe aldıkları ücretli bakım vericileri artık çalıştırmamaya karar vermektedir. Bu da aile üyesi olarak bakım vericilerin demanslı bireylerle geçirdikleri sürenin artmasına 
ve başa çıkma konusunda endişeye, gerginliğe, tükenmişliğe ve hatta istismara neden olabilmektedir. Daha uzakta olan akrabalar ve arkadaşları salgın sürecinde demanslı bireyde meydana gelen değişiklikleri ve destek ihtiyacını fark edememektedir. İnformal bakım vericiler ve/veya demanslı bireyler için mevcut destek kaynaklarının bazıları pandemi sürecinde kesintiye uğramakta bir kısmı da online (çevrimiçi) olarak devam ettirilemeye çalışılmaktadır. Demanslı bireylere bakım veren bireylerin çoğunu yaşlı bireyler oluşturmaktadır. Bu nedenle internet erişimi veya kullanımı konusunda kendilerine güvenmiyor olabilirler. Dil sorunu, düşük eğitim düzeyi, anlama ile ilgili sorunlar, destek alabileceğine dair güven eksikliği gibi nedenlerden dolayı da bazı bakım verenler (ve demanslı bireylerin kendileri) mevcut ve pandemi sürecinde sunulan destek kaynakları hakkında yeterli bilgi alamamaktadırlar. Pandemi süreci öncesinde formal bakım verenler tarafından sağlanan belirli hizmetlerin (banyo, kişisel bakım, enteral besleme...) sekteye uğraması nedeniyle informal bakım verenler bu bakımları sağlamak zorunda kalmakta ve uygun bakımı verip vermediği konusunda endişe duyabilmektedir. İleri yaşlı ve kendi sağlı sorunları da olan bakım verenler, kendilerini izole etme ihtiyaçları ve pandemi sürecinde mevcut olan sınırlı hizmetler nedeniyle bakım sorumluluklarını yerine getirmede daha fazla zorluk yaşayabilmektedir. Kısıtlamaların süresinin belirsiz olması ve bakım sürecine ara verememeleri bakım verenleri psikolojik olarak zorlayabilmektedir (9). Bakım verenlerin bu süreçte psikolojik ve fiziksel yükünde önemli bir artış olduğu belirtilmektedir (18).

\section{Bakım Verenlere Yönelik Öneriler}

Pandemi öncesinde ve sürecinde demanslı bireyler çoğunlukla evlerinde ya da uzun süreli bakım hizmeti veren kurumlarda bakılmaktadırlar. Az sayıda demanslı birey ise akut gelişen durumlar nedeniyle hastanede yatarak tedavi edilmektedirler. Bu makalede evde bakım veren aile üyeleri, hastanede ya da kurumda bakım veren sağlı profesyonelleri için öneriler sunulmaktadır. Ayrıca sağlık profesyonelleri sıklıkla evde bakım gerçekleştiren aile üyelerinin soruları ile karşı karşıya oldukları için onların aile eğitimlerine destek olmak amacı da içermektedir.

Bakım verenler, kendilerinde ve bakımını sürdürmekte oldukları demanslı bireylerde grip veya zatürre benzeri semptomlara dikkat etmeli ve en kısa zamanda sağlık profesyonellerine danışmalıdır. Hasta bireylerle yakın temastan kaçınılmalıdır. Ayrıca mukoz membranlardan girişi önlemek için göz, burun ve ağza dokunmaktan kaçınılması, öksürme ve hapşırma durumunda tek kullanımlık mendil kullanılması ve hemen sonrasında çöpe atılması gerekmektedir. Sık dokunulan nesneler ve yüzeyler temizleme spreyi veya dezenfektanla temizlenmeli, özellikle yemek yemeden önce ve öksürme ve hapşırma sonrası ellerin en az 20 saniye sabun ve suyla yıkanmalı, eğer su ve sabuna hemen ulaşılamıyorsa en az \%60 alkol içeren alkol bazlı el dezenfektanları kullanılmalıdır. Eller gözle görünür derecede kirliyse mutlaka su ve sabun ile yıkanmalıdır (12). Bireyin demans evresine göre pandemi süreci ve sürece uyum sağlanması için yapılması gerekenler konuşulabilir (11). Demanslı bireyleri COVID-19 salgın sürecinden korumak için yapılması gereken hijyen uygulamalarını hatırlatmak için yazılı hatırlatıcılar kullanılabilir. Örneğin; ellerini 20 saniye sabunla yıkamalarını hatırlatmak için banyoya ve evin çeşitli yerlerine görseller yerleştirilebilir. Demanslı bireylere el yıkamayı nasıl yapması gerektiği detaylı olarak gösterilebilir. Eğer demanslı birey banyoya ulaşmakta zorlanıyor ya da ellerini yıkamakta zorlanıyorsa, alternatif olarak en az \%60 alkol içeren el dezenfektanları kullanılabilir (12). Eğer bireyi üzeceği ya da korkmasına neden olacağ1 düşünülüyorsa pandemi süreci konusunda konuşulmaması önerilmektedir. Demanslı bireylerde konfüzyonun artması genellikle herhangi bir hastalığın ilk belirtisidir. Eğer hızla artan bir konfüzyon varsa fakat nefes almakta güçlük çekmiyorsa ve/veya ateşi çok yüksek değilse doğrudan acil servise gitmek yerine sağlık profesyonellerine danışılması gerekmektedir. Primer bakım verenin hastalanması durumunda, bakım yönetimi için alternatif planların yapılması önerilmektedir (12).

Bakım verenlerin öncelikle kendi sağlıklarını korumaları bakım verme sürecine devam edebilmeleri açısından önemlidir. Bu zorlu süreçte bakım verenlerin refah düzeylerinin artmasına katkı sağlayan destek gruplar gibi sosyal destek hizmetlerine erişimi hayati öneme sahiptir. Bakım verenler, destek gruplara katılmanın bakım vermenin duygusal yönüyle başa çıkma konusunda onlara yardımcı olduğunu belirtmektedir. Destek gruplar vasıtasıyla bakım verenler, diğer bakım verenlerle deneyimlerini paylaşabilmekte, hastalık ve mevcut kaynaklar hakkında bilgi edinebilmektedir (19). Akıllı telefonlar gibi tele tıp ve dijital teknoloji cihazları, uzaktan takip ve bakımda yararlı olabilmektedir. Video konferans veya akıllı telefon uygulamaları, demanslı bireylere ve bakım verenlerine destek sağlamak ve klinik ilerlemeyi takip etmek için kullanılabilir (20). Web tabanlı eğitim ve psikoeğitim programlarının bakım verenlerin yükünü azalttığı aynı zamanda da bakım verme konusunda bilgi ve yeterliliklerini geliştirdiği belirtilmektedir $(21,22)$. Ayrıca, mobil kısa mesajlaşma, video kaydı ve sohbet forumları da bakım verenlerin belirli ihtiyaçlarını karşılamak için yararlı olabilmektedir (20). Belirsizliklerle karşı karşıya kalındığında depresyon ve anksiyeteden korunmak için güvenilir kaynaklardan güncel bilgiyi takip etme, en kötü ve en iyi durum senaryoları üzerinde durulmaması, düşüncelerin yazılması veya güvenilen biriyle konuşulması, sosyal medya ile etkileşimlerin sürdürülmesi gibi stratejiler uygulanabilir. Bu stratejiler; özellikle düzenli uyku ve egzersiz, hidrasyonun sürdürülmesi, dengeli beslenme, alkol alımının ve medyaya maruz kalmanın sınırlandırılmasıyla birleştirildiğinde, bakım verenlerin psikolojik dayanıklılığını ve mental sağlığını iyileştireceği belirtilmektedir (11).

Alzheimer Europe (2020) bakım verenlere ve sağlık profesyonellerine öneriler sunmaktadır.

Sağlık Profesyonelleri Demanslı Bireylere ve İformal Bakım Verenlerine Aşă̆ıda Belirtilen Konularda Destek Să̆layabilirler:

- Demanslı bireylere ve bakım verenlerine COVID-19 belirti ve bulguları hakkında bilgi verilmesi,

- Bakım verenlere demanslı bireylerde konfüzyonun artmasının genellikle herhangi bir hastalığın ilk semptomu olabileceğinin vurgulanması,

- Demanslı bireylerin ve bakım verenlerinin farklı eğitim seviyelerine, internet kullanım ve dil becerilerine, farklı etnik, kültürel ve dini geçmişlere sahip olduklarını göz önünde bulundurularak erişilebilir bir stil ve formatta nasıl ve nerede yardım isteyecekleri hakkında bilgi verilmesi,

- Demanslı bireylerin ve bakım verenlerinin pandemi sürecinde mevcut olan sağlık hizmetlerin farkında olmaları ve bunlara nasıl erişecekleri hakkında bilgi verilmesi, 
- Demanslı bireyleri hem pratik hem de duygusal olarak nasıl destekleyecekleri konusunda bakım verenlere rehberlik etmek, önerilerde bulunmak (örneğin; günün nasıl yapılandırılabileceği ve demanslı bireyin aktif tutulabileceği, mümkün olduğunda temiz havaya çıkarabileceği, ilaçların kullanımı ve diğer bireylerle telefonla veya görüntülü olarak sosyal temasın sürdürebileceği...) ve bakım verenlerin kendi ihtiyaçlarına nasıl karşılayabilecekleri hakkında bilgilendirilmesi,

- Demanslı bireyler ve bakım verenleri için telefon destek hatlarının ve online desteğin sürdürülmesi,

- Bakım verenleri yararlı uygulamalar ve çevrimiçi videolara (örneğin; pratik tavsiye, bilgi, danışmanlık, sandalye egzersizleri, yoga, formda kalmak, bilişsel uyarım...) teşvik etmek için Zoom, Skype ve web radyosu gibi güncel teknolojinin kullanılması,

- İnternet erişimine dayanmayan farklı iletişim yöntemlerinin (örneğin; basılı broşürler, kırsal kesimdeki bireylere ulaşmak için yerel radyo, dini topluluklara ulaşmak için cami, cem evleri, kiliselerden mesajlar, gazete makaleleri ve telefon görüşmeleri...) araştırılması ve uygulanması,

- Demans gönüllülerinden ve yerel şubelerden gelen desteği (örneğin; alışveriş, yemek ve gerekli onarımlar, ilaç toplamak, köpekleri yürüyüşe çıkarmak...) koordine edilmesi önerilmektedir.

Evde Formal Bakım Veren Hizmeti Alan veya Almayı Planlayan Bakım Verenlere Öneriler:

- Evde formal bakım hizmeti verenlerle iletişime geçilerek COVID-19'un yayılımını azaltmak için alınan önlemleri öğrenmeleri,

- Evde formal bakım hizmeti verenlerin vücut 1 sısın eve girmeden önce ölçülmesi, $38{ }^{\circ} \mathrm{C}$ üzerinde olan bireylerin eve alınmamaları,

- Evde formal bakım hizmeti verenlere COVID-19 testi pozitif olan biriyle temaslı olup olmadıklarını sormaları ve eğer temaslı ise bu kişilerden bakım hizmeti almamaları,

- Evde formal bakım hizmeti verenlerin eve vardıklarında ve evde geçirdikleri süre boyunca ellerini düzenli olarak yıkamalarının hatırlatılması,

- Evde formal bakım hizmeti verenlerden evde bulundukları süre boyunca da maske takmasının istenmesi önerilmektedir. Bu önerilere uyulsa bile eve gelen herhangi birinin COVID-19 virüsünün yayılma riskini artırdığı unutulmamalıdır.

Kurumsal Bakım Hizmeti Alan Bakım Verenler İçin Öneriler:

Bakım hizmeti veren kurum/lar bölgedeki salgın durumuna göre ziyaretçilere izin verebilir ya da ziyaretçi kısıtlaması yapabilirler (8). Bu durum bakım hizmeti alan bireyleri korumak için olsa da aile üyeleri için yakınlarını görmemek zorlayıcı olabilmektedir. Ayrıca bu kurumlarda grup faaliyetleri de yasaklanmaktadır. Sonuç olarak kurumsal bakım alan bireyler sosyal olarak daha izole hale gelmektedir (8).

- Ziyarete izin verilmiyorsa, bakım hizmeti veren kuruma demanslı bireyle nasıl iletişim kurulabileceğinin (telefon görüşmesi, görüntülü konuşma ve hatta e-posta seçenekleri sunabilirler) sorulması,

- Eğer demanslı birey aramalara veya görüntülü konuşmalara katılmakta zorlanıyorsa, kuruma birey hakkında güncel bilgileri elde edebilmek için kurum personeli ile nasıl iletişime geçilebileceği sorulması,

- Kuruma COVID-19 salgın yönetimine ilişkin aldığı önlemler hakkında danışılması,

- Acil durumlarda ulaşılabilinmesi için demanslı bireyin aile üyeleri ve arkadaşlarının iletişim bilgilerinin güncel olması,

- Herhangi bir hastalık belirtisi veya semptom gösteriliyorsa kurum ziyareti yapılmaması önerilmektedir.

Demanslı Birey Hastanede Kallyorsa Bakım Verenler İçin Öneriler:

COVID-19 salgınında enfekte olan demanslı bireyler hastanelerde yoğun bakımda tedavi görmek durumunda kalabilirler. Yeni bir ortam artan strese ve davranışsal sorunlar yol açabilmektedir (23). COVID-19'un belirgin bir klinik özelliği olan hipoksinin neden olduğu deliryum, demanslı bireylerin sağlık sorunlarını ve bakım gereksinimini artırabilmektedir (8). Birçok hastane COVID-19 virüsünün yayılımını engellemek ve hem hastaları hem de sağlık çalışanlarını korumak için ziyaretçileri kısıtlamakta ya da izin vermemektedir.

Eğer bireyin ziyareti mümkün ise,

- Hastaneye COVID-19 salgın yönetimine ilişkin aldığı önlemler hakkında danışılması,

- Mutlaka maske kullanılması,

- Ellerin düzenli olarak yıkanması ve yüze dokunmaktan kaçınılması,

- Demanslı bireyin odasına ziyaret süresinin sınırlandırılması ve hastaneden mümkün olan en kısa zamanda ayrılması önerilmektedir.

Eğer bireyin ziyareti mümkün değilse,

- Demanslı bireyle telefon veya görüntülü konuşma yoluyla iletişim kurulması,

- Demanslı bireyin yakınlarının iletişim bilgilerinin sağlık çalışanlarıyla paylaşılması önerilmektedir.

\section{Sonuç}

COVID-19 pandemisi tüm dünyada olduğu gibi ülkemizde de en önemli sağlık sorunlarının başında yer almaktadır. Demans hastalığına sahip olmanın COVID-19'a yakalanma riskini artırdığı düşünülmemektedir ancak demanslı bireylerin çoğunun yaşlı olması nedeniyle virüsten olumsuz etkilenme riski daha fazladır. Fakat pandemi sürecinde hem demanslı bireyler hem de bakım verenler birçok yönden olumsuz şekilde etkilenmektedir. Aile üyeleri pandemi sürecinde hem kendi gereksinimleri hem de bakımından sorumlu oldukları bireyin gereksinimleri arasında sıkışmış ve sosyal izolasyon ve kısıtlamalar nedeniyle gereksinimlerini ifade edememişlerdir. Sağlık profesyonellerinin ailelerinin içinde bulundukları durumun güçlüğünün farkında olup salgından korunmaya ek olarak, ruh sağlığının korunması konusunda da bilgi verilmeli ve psikososyal destek sağlanmalıdır. $\mathrm{Bu}$ derlemeyle; pandemi sürecinde demanslı bireyin bakımından sorumlu sağlık profesyonellerinin ve aile üyelerinin bakım süreçlerinde kullanabileceği pratik öneriler sunarak onların yollarına ışı tutacağı düşünülmektedir. 


\section{Bilgilendirme}

Makalenin sorumlu yazarı MAA fikir, tasarım, literatür taraması, metnin yazımı ve kaynakların derlenmesinden sorumlu olup; ÖK fikir, tasarım, literatür taraması ve metnin yazımı; BAS fikir ve eleştirel inceleme basamaklarında makaleye katkılarını sunmuştur. Metnin oluşturulmasında yararlanılan tüm çalışmalar araştırma ve yayın etiğine uygun şekilde kaynak listesinde bildirilmiştir. Araştırmacılar arasında herhangi bir kişi ya da kurum ile çıkar çatışması bulunmamaktadır ve derlemede herhangi bir fon desteği alınmamıştır. 
1. World Health Organization (WHO). Coronovirus disease (COVID-19) pandemic (2020) [online]. URL: https://www.who.int/emergencies/diseases/novel-coronavirus-2019. 24 Mayıs 2021

2. Banerjee D. The COVID-19 outbreak: Crucial role the psychiatrists can play. Asian J Psychiatr 2020;50:102014.

3. Guan WJ, Ni ZY, Hu Y, Liang WH, Ou CQ, He JX, et al. Clinical characteristics of coronavirus disease 2019 in China. N Engl J Med 2020;382(18):1708-1720.

4. Etard JF, Vanhems P, Atlani-Duault L, Ecochard R. Potential lethal outbreak of coronavirus disease (COVID-19) among the elderly in retirement homes and long-term facilities, France, March 2020. Eurosurveillance 2020;25(15):1-3.

5. Kaiser Family Foundation (KFF). 8 in 10 People who have died of COVID-19 were age 65 or older - but the share varies by state (2020) [online]. URL: https://www.kff.org/coronavirus-covid-19/press-release/8-in-10-people-who-have-died-ofcovid-19-were-age-65-or-older-but-the-share-varies-by-state/. 24 Mayıs 2021

6. Fox NC, Petersen RC. The G8 dementia research summit--a starter for eight? The Lancet 2013;382:1968-1969.

7. Alzheimer's Disease International. World Alzheimer Report 2019 Attitudes to dementia [online]. URL: https://www.alzint.org/u/WorldAlzheimerReport2019.pdf. 24 Mayis 2021

8. Wang H, Li T, Barbarino P, Gauthier S, Brodaty H, Molinuevo JL, et al. Dementia care during COVID-19. The Lancet 2020;395(10231):1190-1191.

9. Alzheimer Europe. Alzheimer Europe recommendations on promoting the wellbeing of people with dementia and carers during the COVID-19 pandemic. Luxemburg: Alzheimer Europe [online]. URL: https://www.alzheimereurope.org/Policy/Our-opinion-on/Wellbeing-of-people-with-dementia-during-COVID-19-pandemic 24 Mayıs 2021

10. Williamson HJ, McCarthy MJ, Garcia YE, Bacon R, Dunn DJ, Baldwin JA. Addressing the needs of rural caregivers of individuals with alzheimer's disease and related dementias during and beyond coronavirus disease 2019 (COVID19). Public Policy Aging Rep 2020;30(4):178-180.

11. Tousi B. Dementia care in the time of COVID-19 pandemic. J Alzheimer's Dis 2020;(Preprint):1-5.

12. Alzheimer's Association. Coronavirus (COVID-19): Tips for Dementia Caregivers (2020) [online]. URL: https://www.alz.org/help-support/caregiving/coronavirus-(covid-19)-tips-for-dementia-care. 24 Mayss 2021

13. Cagnin A, Di Lorenzo R, Marra C, Bonanni L, Cupidi C, Laganà V, et al. Behavioral and psychological effects of coronavirus disease-19 quarantine in patients with dementia. Front Psychiatry 2020;11:1-15.

14. Brown EE, Kumar S, Rajji TK, Pollock BG, Mulsant BH. Anticipating and mitigating the impact of COVID-19 pandemic on Alzheimer's disease and related dementias. Am J Geriatr Psychiatry 2020;28(7):712-721.

15. Mok VC, Pendlebury S, Wong A, Alladi S, Au L, Bath PM, et al. Tackling challenges in care of Alzheimer's disease and other dementias amid the COVID-19 pandemic, now and in the future. Alzheimer's \& Dementia 2020;16(11):1571-1581.

16. Song H, Sieurin J, Wirdefeldt K, Pedersen NL, Almqvist C, Larsson H, et al. Association of stress-related disorders with subsequent neurodegenerative diseases. JAMA Neurology 2020;77(6):700-709.

17. Vaitheswaran S, Lakshminarayanan M, Ramanujam V, Sargunan S, Venkatesan S. Experiences and needs of caregivers of persons with dementia in India during the COVID-19 pandemic-A qualitative study. Am J Geriatr Psychiatry 2020;28(11):1185-1194.

18. Tsapanou A, Papatriantafyllou JD, Yiannopoulou K, Sali D, Kalligerou F, Ntanasi E, et al. The impact of COVID-19 pandemic on people with mild cognitive impairment/dementia and on their caregivers. Int $\mathrm{J}$ Geriatr Psychiatry 2021;36(4):583-587.

19. Giebel CM, Challis DJ, Montaldi D. A revised interview for deterioration in daily living activities in dementia reveals the relationship between social activities and well-being. Dementia 2016;15(5):1068-1081.

20. Cuffaro L, Di Lorenzo F, Bonavita S, Tedeschi G, Leocani L, Lavorgna L. Dementia care and COVID-19 pandemic: A necessary digital revolution. Neurological Sciences 2020;41(8):1977-1979.

21. Godwin KM, Mills WL, Anderson JA, Kunik ME. Technology-driven interventions for caregivers of persons with dementia: A systematic review. Am J Alzheimers Dis Other Demen 2013;28(3):216-222.

22. Finkel S, Czaja SJ, Martinovich Z, Harris C, Pezzuto D, Schulz R. E-care: A telecommunications technology intervention for family caregivers of dementia patients. Am J Geriatr Psychiatry 2007;15(5):443-448.

23. Kales HC, Lyketsos CG, Miller EM, Ballard C. Management of behavioral and psychological symptoms in people with Alzheimer's disease: An international Delphi consensus. Int Psychogeriatr 2019;31(1):83-90. 